\title{
The Protective Roles of Vitamin E and $\alpha$-Lipoic Acid Against Nephrotoxicity, Lipid Peroxidation, and Inflammatory Damage Induced by Gold Nanoparticles
}

This article was published in the following Dove Press journal:

International Journal of Nanomedicine

\section{Mohamed Anwar K \\ Abdelhalim (D) \\ Huda AY Qaid \\ Yanallah H Al-Mohy \\ Magdi Mohamed Ghannam}

Department of Physics and Astronomy, College of Science, King Saud University, Riyadh, Saudi Arabia
Correspondence: Mohamed Anwar K Abdelhalim

Biomedical Physics, Department of

Physics and Astronomy, College of

Science, King Saud University, P.O. 2455,

Riyadh II45I, Saudi Arabia

Tel +966509649633

Email abdelhalimmak@yahoo.com
Background: Recently, use of nanotechnology in biomedical applications such as drug delivery and diagnostic and therapeutic tools has increased greatly. This study evaluated gold nanoparticle (GNPs)-induced nephrotoxic effects in rats in vivo, and examined protective effects of alpha-lipoic acid ( $\alpha$-Lip) and Vitamin E (Vit E) against nephrotoxicity, lipid peroxidation, and inflammatory kidney damage induced by GNPs.

Materials and Methods: Twenty-four male Wistar-Kyoto rats (220-240 g, 12 weeks old) were dosed with $50 \mu \mathrm{L}$ of $10 \mathrm{~nm}$ GNPs administered intraperitoneally with or without $200 \mathrm{mg} /$ $\mathrm{kg} /$ day Vit E or $200 \mathrm{mg} / \mathrm{kg} /$ day $\alpha$-Lip. Serum was prepared for biochemical analyses. Kidney function was evaluated through measurement of creatinine (CR), uric acid (URIC), and blood urea nitrogen (BUN). Oxidative stress and lipid peroxidation were evaluated by measurement of reduced glutathione (GSH) and malondialdehyde (MDA) in kidney tissue homogenates.

Results and Conclusions: The results showed a significant rise in serum kidney function biomarkers including urea, URIC, CR, and BUN in GNP-treated rats compared to normal control rats. Furthermore, GNPs led to decreased GSH and elevated MDA levels. Vit E or $\alpha-$ Lip supplementation showed a beneficial effect against nephrotoxicity, lipid peroxidation, and inflammatory kidney damage induced by GNPs. This study suggests that use of natural antioxidants in combination with GNPs may be a useful tool in preventing GNPs toxicity.

Keywords: gold nanoparticles, Vitamin E, alpha-lipoic acid, nephrotoxicity, lipid peroxidation, natural antioxidants

\section{Introduction}

Nanoparticles (NPs) are potentially dangerous chemical substances that adhere to cell membranes and permeate animal organs. Nanoparticle surfaces can be changed and adjusted to the environmental transformation. ${ }^{1}$

Distribution of NPs in the liver, spleen, cerebrum, heart, and kidney may result in impaired function. A previous study showed that the dimensions and surface area of nanoparticles are important factors in increased reactive oxygen species (ROS) production $^{2}$. Exposure to GNPs can result in inflammation, death of tubular epithelial cells, increased capillary permeability, blood loss, and inflammatory cell infiltration. ${ }^{3-8}$

Vit $\mathrm{E}$ is a critical fat-soluble antioxidant that supports mitosis, immune function, speeds of blood clotting, and serves as a natural defense against oxidative stress in tissues. Vit E also contributes to cell membrane function, elasticity, and integrity. 9,10 
Alpha-lipoic acid is a potent antioxidant and is a substrate for the pyruvate dehydrogenase complex found in mitochondria of hepatic, renal, and cardiac tissues. $\alpha$-Lip can be reduced to dihydrolipoic acid, which has ROS scavenging activity, and maintains GSH and vitamins $\mathrm{C}$ and $\mathrm{E}$, which are exogenous, in the reduced state. ${ }^{11}$ Prevention of toxicity induced by GNPs in vivo has not been reported. Therefore, this study aims to confirm nephrotoxicity, lipid peroxidation, and inflammatory kidney damage caused by GNPs, and to assess the role of Vit $\mathrm{E}$ and $\alpha$-Lip acid in inhibiting or preventing alterations induced by GNPs in the kidney organ.

\section{Materials and Methods GNPs and Antioxidants}

Size and morphology of 10nm GNPs (products MKN-Au -010; M K IPEX Corp; Divn MK Nano, CANADA) have shown spherical shape with mean size $9.45 \pm 1.33 \mathrm{~nm}$ as calculated from the images taken by transmission electron microscope (TEM). The GNPs have been distributed in homogenous way through the solution. Vit E and $\alpha$-Lip were purchased from Sigma-Aldrich Co. (St. Louis, MO, USA). The Vit E dose was $100 \mathrm{mg} / \mathrm{Kg} \mathrm{BW} /$ day, and the $\alpha-$ Lip acid dose was $200 \mathrm{mg} / \mathrm{Kg} \mathrm{BW} /$ day, according to AlRasheed et al., 2014. ${ }^{12}$

\section{Animals}

Twenty-four 12-week-old Wistar-Kyoto male rats (220-240 g) were acquired from the College of Pharmacy, Animal Centre, KSU. The rats were kept in cages under standard conditions $\left(22 \pm 5^{\circ} \mathrm{C}\right.$ temperature, $55 \pm 5 \%$ humidity, $12 \mathrm{hrs}$ light/dark cycle). Rats were fed a regular rodent diet. The KSU Animal Use Committee approved the animal experiments, and all experiments were conducted in accordance with the committee's guidelines approved by KSU Local Animal Care.

\section{Experimental Design}

Rats were acclimatized for 2 days, fasted for 24 hrs before injection, and randomly divided into four groups ( $\mathrm{n}=6$ each). The first group (G1; healthy rats) did not receive GNPs and served as a control. The second group (G2) was treated daily by intraperitoneal injection with $50 \mu \mathrm{L}$ of $10 \mathrm{~nm}$ GNPs for 7 consecutive days. The third group (G3) was treated with $10 \mathrm{~nm}$ GNPs $(50 \mu \mathrm{L})$ plus $100 \mathrm{mg} / \mathrm{Kg}$ BW/day of Vit E for 7 consecutive days. The fourth group (G4) was treated with $10 \mathrm{~nm}$ GNPs $(50 \mu \mathrm{L})$ plus $200 \mathrm{mg} / \mathrm{Kg} \mathrm{BW} /$ day of $\alpha$-Lip for 7 consecutive days.

\section{Blood Sampling and Tissue Preparation}

Twenty-four hours after the final dose, rats were denied access to food for 12-14 hrs, then sacrificed. Blood samples were obtained from each rat and placed into Pasteurized tubes for serum separation. Samples were centrifuged at $3,000 \mathrm{rcf}$ for $10 \mathrm{mins}$, and serum was stored at $-80^{\circ} \mathrm{C}$ until use. Kidney tissues were collected and harvested by the midline incision technique, washed in ice-cold iso-osmotic saline, homogenized, and frozen at $-80^{\circ} \mathrm{C}$ until use.

\section{Serum Kidney Function Biomarkers}

To assay kidney function, blood urea nitrogen (BUN), creatinine (CR), and uric acid (URIC) levels in serum were determined using a biochemical auto-analyser (Type 7170, Hitachi).

\section{Oxidative Stress Biomarkers Reduced Glutathione (GSH) Level Determination}

The level of reduced glutathione (GSH) in the renal tissues was evaluated enzymatically according to Griffith, $1980 .{ }^{13}$ Tissues were homogenized in $0.2 \mathrm{M}$ ice-cold perchloric acid containing EDTA $(0.01 \%)$, then centrifuged at 10,000 rcf for 5 mins. One hundred microliters of supernatant was added to a spectrophotometer cuvette containing $100 \mu \mathrm{L}$ of $6 \mathrm{mM}$ 5,5-dithiobis-2-nitrobenzoic acid, $800 \mu \mathrm{L}$ of $0.3 \mathrm{mM}$ reduced $\mathrm{NADPH}$, and $10 \mu \mathrm{L}$ of 50 units $/ \mathrm{mL}$ glutathione reductase prepared fresh in $\mathrm{pH} 7.5$ phosphate buffer. Absorbance was determined at $412 \mathrm{~nm}$ for 120 mins at $30^{\circ} \mathrm{C}$. Glutathione was assayed by comparing absorbance of the test solution to a glutathione standard.

\section{Determination of Malondialdehyde (MDA)}

Malondialdehyde (MDA) levels were measured as a marker of fatty acid peroxidation index in various organs using the spectrophotometric method described by Hochstein and Utley (1967). Tissues were weighed and homogenized (10\% w/v) in $0.15 \mathrm{M}$ frozen potassium chloride $(\mathrm{KOH})$ with a potter homogenizer and motor-driven Teflon pestle. One milliliter of tissue homogenate was incubated at $37^{\circ} \mathrm{C}$ for $2 \mathrm{hrs}$ in a shaker. One milliliter of $10 \%(\mathrm{w} / \mathrm{v})$ trichloroacetic acid added to the homogenate, and the mixture was centrifuged at $3000 \mathrm{rcf}$ for $10 \mathrm{mins}$. One milliliter of the supernatant was mixed with one $\mathrm{mL}$ of $0.67 \%(\mathrm{w} / \mathrm{v})$ 2-thiobarbituric acid and placed in a hot water bath for 10 mins, then allowed to cool. Following cooling, $1 \mathrm{~mL}$ of distilled water was added. The absorbance was determined at $535 \mathrm{~nm}$, and malondialdehyde level was calculated using tetraethoxypropane (TEP) as a standard. 


\section{Statistical Analysis}

Data obtained were presented as mean \pm SE. To test for the difference between the means, one-way analysis of variance (ANOVA) was used, followed by Bonferroni multiple differences post hoc test, with significance determined by $\mathrm{p} \leq 0.05$ and $* * \mathrm{p} \leq 0.001$.

\section{Results}

Figure 1 shows a major increase in serum creatinine level in the GNPs group $(0.57 \pm 0.02 \mathrm{mg} / \mathrm{dL})$ compared to the control group $(0.43 \pm 0.03 \mathrm{mg} / \mathrm{dL})$. Group 3 $($ GNPs + Vit E) and group 4 (GNPs $+\alpha$-Lip) significantly reduced the level of creatinine to $0.42 \pm 0.02 \mathrm{mg} /$ $\mathrm{dL}$ and $0.43 \pm 0.02 \mathrm{mg} / \mathrm{dL}$, respectively. Administration of $\alpha$-Lip or Vit E with GNPs blocked GNPs-induced increases in creatinine.

Figure 2 shows serum urea level of control (G1), GNPs (G2), G3, and G4 rats. Serum urea in G1 was $18.08 \pm 0.93 \mathrm{mg} / \mathrm{dL}$. After 7 days of intraperitoneal administration of GNPs, the mean level of urea increased significantly to $23.28 \pm 1.03 \mathrm{mg} / \mathrm{dL}(* * \mathrm{p}<0.01)$, contributing to renal damage. Administration of Vit E + GNPs (G3) and $\alpha$-Lip + GNPs (G4) significantly reduced the GNPs-induced elevation of urea to $19.52 \pm 0.88 \mathrm{mg} / \mathrm{dL}$, $20.22 \pm 0.62 \mathrm{mg} / \mathrm{dL}$, respectively.

Figure 3 shows increased uric acid levels in the GNPs group $(1.55 \pm 0.75 \mathrm{mg} / \mathrm{dL})$ compared with the control group $(1.10 \pm 0.98 \mathrm{mg} / \mathrm{dL})$. Administration of Vit E + GNPs (G3)

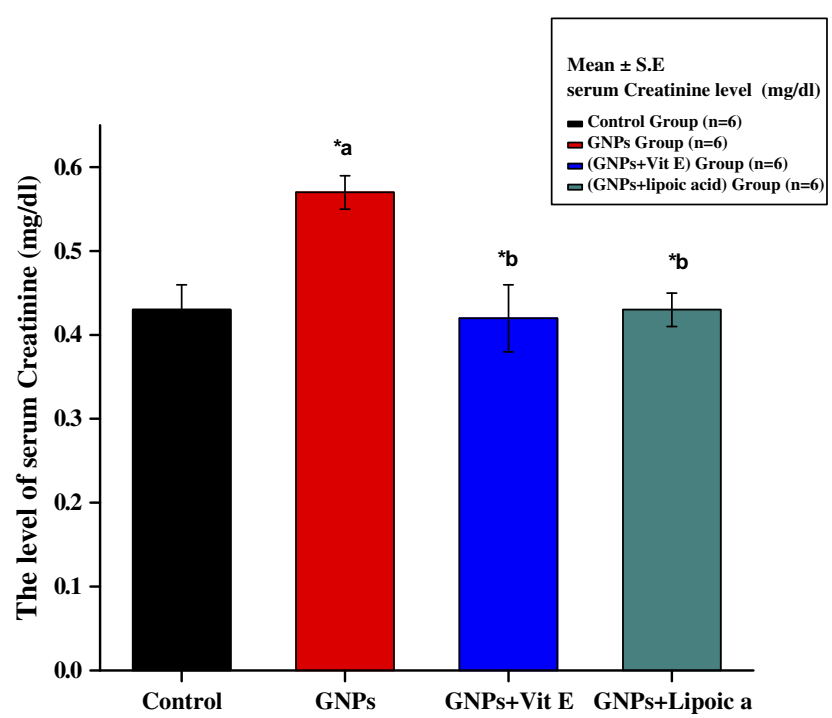

Figure I Effect of GNPs, GNPs + Vit E, and GNPs + $\boldsymbol{\alpha}$-Lip on serum creatinine level in rats. *a represents significance between the control group and the GNPs groups $(p<0.05)$. *b represents significance between the GNPs and the other groups $(p<0.05)$.

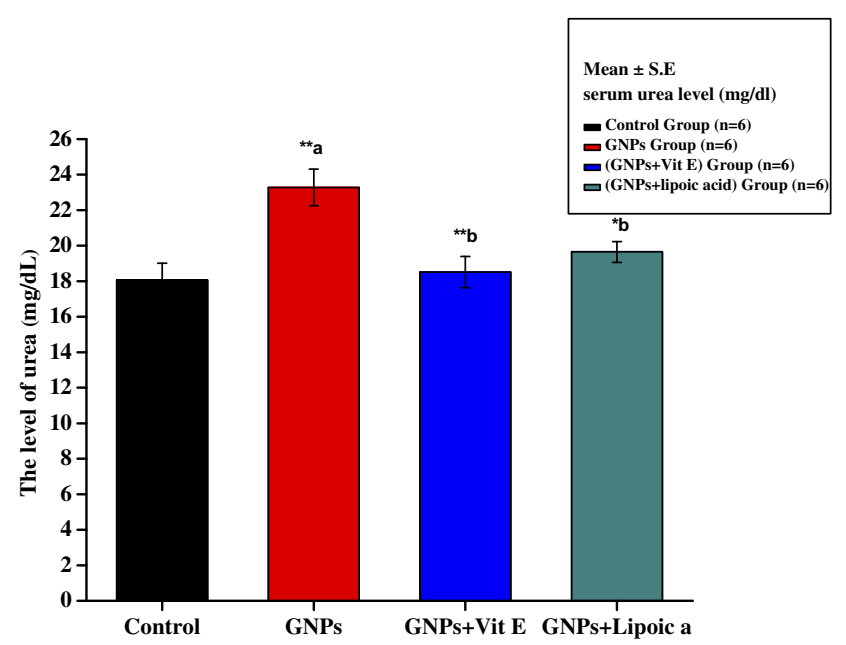

Figure 2 Effect of GNPs, GNPs + Vit E, and GNPs + $\boldsymbol{\alpha}$-Lip on serum urea level in rats. **a significant value $(\mathrm{p}<0.001)$. *b represents significance between the GNPs and the other groups $(p<0.05),{ }^{*}$ b significant value $p<0.00 \mathrm{I}$ : the data were highly significant at this value.

and $\alpha$-Lip + GNPs (G4) significantly reduced kidney uric acid levels to $1.05 \pm 0.85 \mathrm{mg} / \mathrm{dL}$ and $1.13 \pm 0.65 \mathrm{mg} / \mathrm{dL}$, respectively, compared to administration of GNPs alone.

Figure 4 shows a significant decrease in kidney GSH level in the GNPs group to $24.20 \pm 0.02 \mu \mathrm{g} / \mathrm{mL}$ compared to $56.85 \pm$ $0.02 \mu \mathrm{g} / \mathrm{mL}$ in the control group. Administration of Vit $\mathrm{E}+$ GNPs (G3) and $\alpha$-Lip + GNPs (G4) significantly elevated GSH levels to $56.12 \pm 0.01 \mu \mathrm{g} / \mathrm{mL}$ and $53.15 \pm 0.02 \mu \mathrm{g} / \mathrm{mL}$, respectively, compared to GNPs alone.

Figure 5 shows a significant increase in the lipid peroxidation product, malondialdehyde (MDA), in rat kidney tissues in response to GNP $(0.27 \pm 0.03 \mu$ moles $/ \mathrm{mL})$ compared to control $(0.07 \pm 0.01 \mu$ moles $/ \mathrm{mL})$. Co-administration of Vit

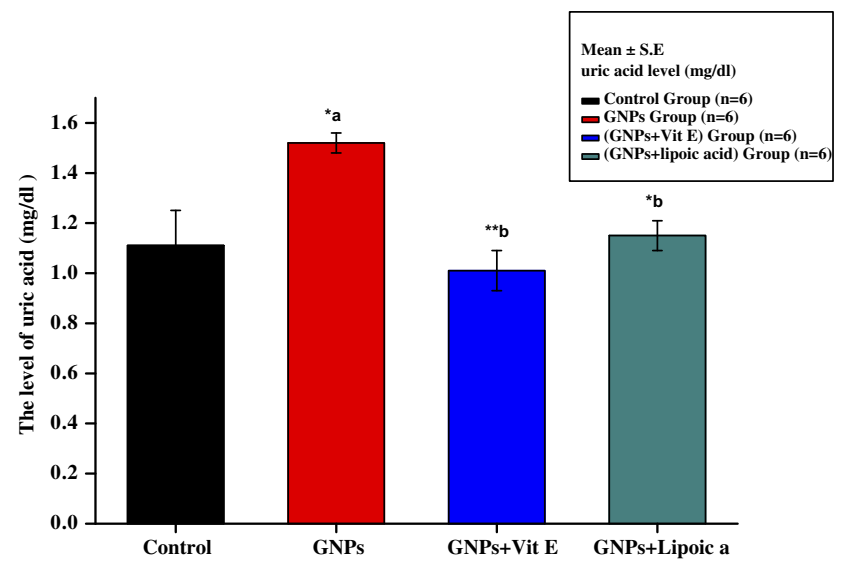

Figure 3 Effect of GNPs, GNPs + Vit E, and GNPs $+\boldsymbol{\alpha}$-Lip on serum uric acid level in rats. *a represents significance between the control group and the GNPs groups $(p<0.05)$. *b represents significance between the GNPs and the other groups $(p<0.05)$, **b significant value $p<0.001$ : the data were highly significant at this value. 


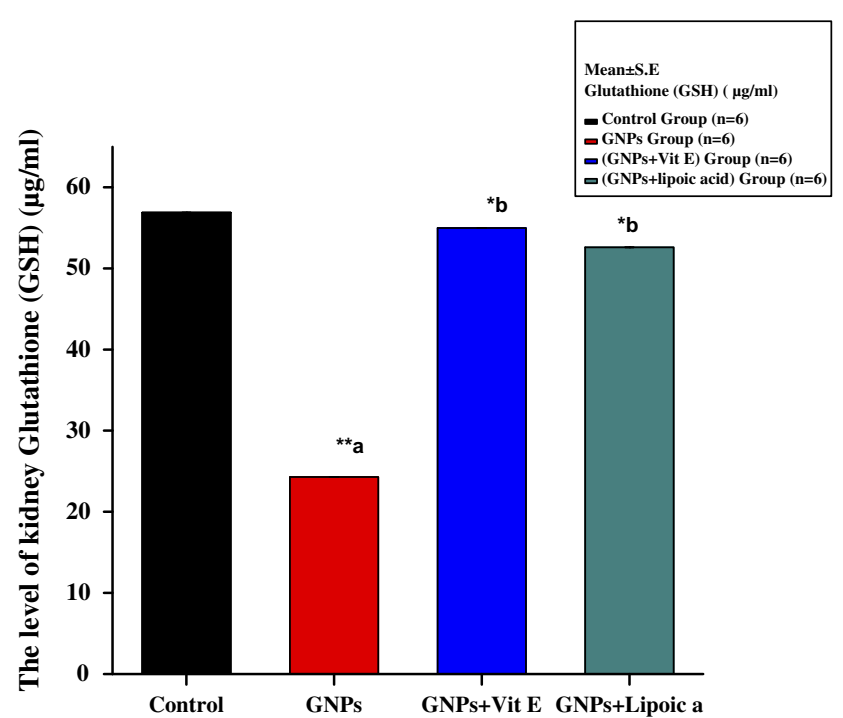

Figure 4 Effect of GNPs, GNPs + Vit E, and GNPs + $\alpha$-Lip on kidney GSH level in rats. **a significant value $(p<0.001)$. *b represents significance between the GNPs and the other groups $(p<0.05)$, ${ }^{*}$ b significant value $p<0.00 \mathrm{I}$ : the data were highly significant at this value.

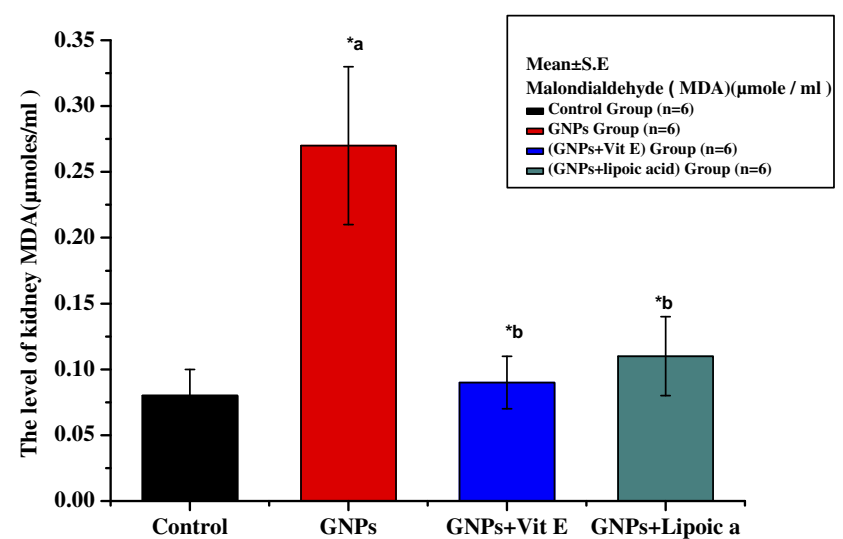

Figure 5 Effect of GNPs, GNPs + Vit E, and GNPs $+\boldsymbol{\alpha}$-Lip on kidney Malondialdehyde level in rats. *a represents significance between the control group and the GNPs groups $(p<0.05)$. *b represents significance between the GNPs and the other groups $(p<0.05)$.

E + GNPs $(G 3)$ and $\alpha$-Lip + GNPs (G4) significantly reduced MDA levels to $0.09 \pm 0.03 \mu$ moles $/ \mathrm{mL}$ and $0.12 \pm 0.02$ $\mu \mathrm{moles} / \mathrm{mL}$, respectively.

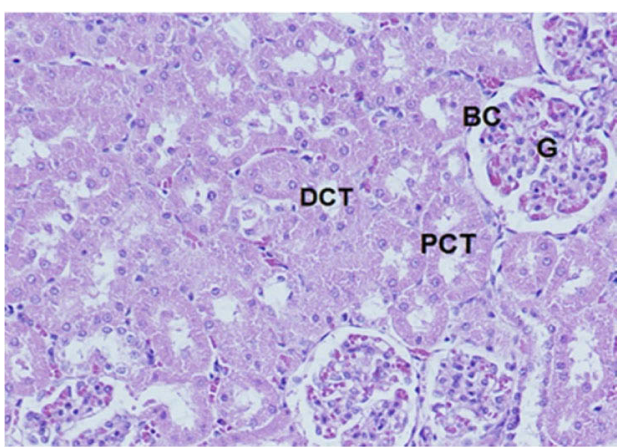

A

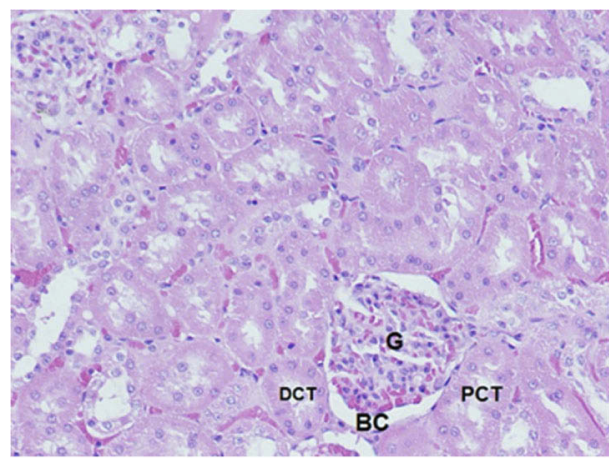

C

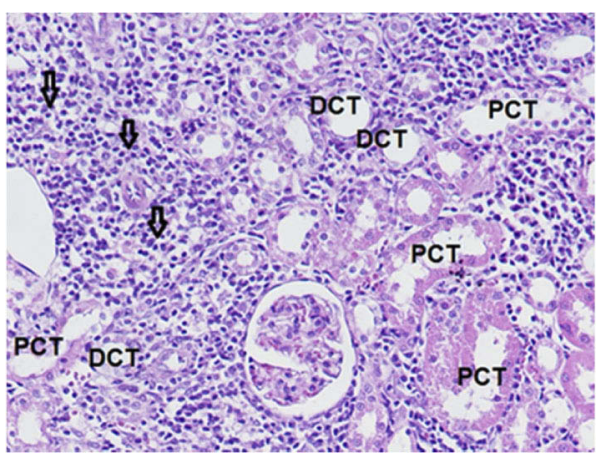

B

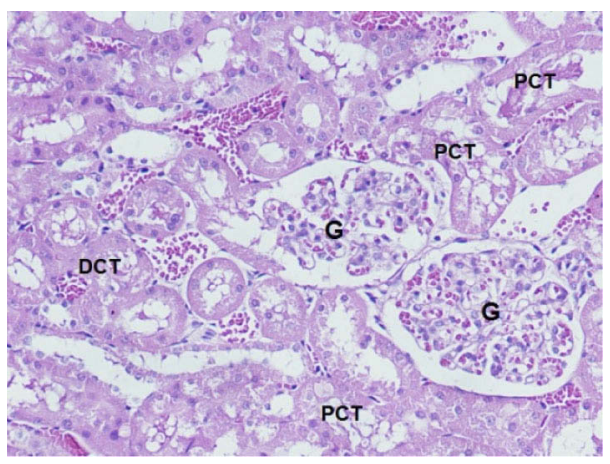

D

Figure 6 Sections in cortex of the kidney (H\&E x 200). (A) Normal control rats (GI) show renal corpuscle consists of glomerulus (G) and a two-layered glomerular Bowman's capsule (BC) that encloses glomerulus; the proximal convoluted tubules (PCT) and distal convoluted tubules (DCT). (B) GNPs-treated rats (G2) show inflammatory cells infiltration, mainly in the interstitial tissue (arrows), vacuolar degeneration surrounding PCT and DCT, tubule necrosis (star), dilation and vacuolar degeneration in PCT and DCT. (C) GNPs + Vitamin E (G3) shows normal renal corpuscle surrounded by normal tubules. (D) GNPs + $\boldsymbol{\alpha}$-lipoic acid (G4) shows vacuolar degeneration in PCT and DCT. 
Figure 6 shows histopathological studies that give more evidences of the nephrotoxic effect of GNPs and the protective effect of Vit E and $\alpha$-Lip.

\section{Discussion}

NPs absorbed into the blood and are cleared by the kidney. ${ }^{14}$ This study confirmed nephrotoxic effects of GNPs. Our research shows that GNPs significantly elevated URIC, BUN, and CR levels compared to the control group. GSH levels in kidney tissues were significantly decreased, while MDA levels were significantly increased.

In serum from rats injected with GNPs, significant increases in $\mathrm{CR}$ and BUN levels compared to control confirmed nephrotoxicity $(p<0.05)$. Vit $\mathrm{E}$ and $\alpha$-Lip significantly reduced serum CR, URIC, and BUN levels compared to rats administered GNPs.

Vit $\mathrm{E}$ disrupts free radical reactions, resulting in formation of antioxidant radicals that are only moderately reactive. As a result, Vit E scavenges free radicals. ${ }^{15}$ Vit E quenches fatty acid peroxidation in membranes due to its radical scavenging ability. ${ }^{16}$ Thus, Vit E serves an essential role in renal tissues against peroxidative injury. ${ }^{17}$

Vit E supplementation may reduce oxidative stress, and also may be useful in reducing heart disease linked to chronic kidney failure. In vivo and in vitro studies have shown that Vit E provides a defense against fatty acid peroxidation and inhibits metal-mediated damage. $\alpha$-Lip increases concentrations of hepatic cysteine and glutathione. $\alpha$-Lip can reduce oxidized vitamin $\mathrm{C}$, helping to maintain antioxidant status. $\alpha$ Lip can boost production of glutathione, the foremost antioxidant in human cells. ${ }^{12,18,19}$

Decrease oxidative stress resulting $\alpha$-Lip or Vit E may be responsible for their anti-inflammatory effects. GSH in kidney tissues decreased significantly after administering of GNPs. In contrast, GSH increased significantly after Vit $\mathrm{E}$ or $\alpha$-Lip administration. GSH functions as a scavenger of poisons and free radicalgenerated species. GSH can also compensate for Vit E deficiency. Previous studies evaluated GSH levels in animals injected with Vit $\mathrm{E}$ or $\alpha$-Lip after zinc nanoparticles injection. ${ }^{12,13,16-18}$

\section{Conclusions}

This study highlights the nephrotoxic effects induced by intraperitoneal administration of GNPs as confirmed by significant increases in serum kidney function markers such as URIC, CR, and BUN. In addition to a significant increase in the fatty acid peroxidation biomarker MDA, GNPs also resulted in significant reduction in the oxidative stress biomarker GSH. Administration of Vit E or $\alpha$-Lip significantly reduced inflammatory kidney damage, lipid peroxidation, and oxidative stress, as determined by reduced serum markers, elevated tissue levels of GSH, and reduced tissue MDA. Our findings showed that Vit E and $\alpha$-Lip are highly potent antioxidants that can protect against the kidney dysfunction, inflammatory damage, lipid peroxidation, and oxidative stress.

\section{Acknowledgments}

The authors would like to extend their sincere appreciation to the Deanship of Scientific Research at King Saud University for funding of this research through the research Group Project No. RGP-285

\section{Disclosure}

The authors report no conflicts of interest in this work.

\section{References}

1. Salata OV. Application of nanoparticles in biology and medicine. $J$ Nanobiotechnol. 2004;2:3. doi:10.1186/1477-3155-2-3

2. Moller P, Jacobsen NR, Folkmann JK, et al. Role of oxidative damage in toxicity of particulates. Free Radical Res. 2010;44(1):1-46. doi:10.3109/10715760903300691

3. Abdelhalim MAK, BM J. Histological alterations in the liver of rats induced by different gold nanoparticles size, dose and exposure duration. J Nanobiotechnology. 2012;10:5. doi:10.1186/14773155-10-5

4. Abdelhalim MAK, Jarrar BM. Renal tissue alterations were size-dependent with smaller ones induced more effects and related to time exposure of gold nanoparticles. Lipids Health Dis. 2011;10:163. doi:10.1186/1476-511X-10-163

5. Abdelhalim MAK. Gold nanoparticles administration induces disarray of heart muscle, hemorrhagic, chronic inflammatory cells infiltrated by small lymphocytes, cytoplasmic vacuolization and congested and dilated blood vessels. Lipids Health Dis. 2011;10:233. doi:10.1186/1476-511X-10-233

6. Moron MS, Depierre J, Mannervik B. Levels of glutathione, glutathione reductase and glutathione $-\mathrm{S}$ - transferase activities in rat lung and liver. Biochem Biophys Acta. 1979;582:67-78. doi:10.1016/0304-4165(79) 90289-7

7. Gupta A, Singh S, Jamal F, Nath MS, Sharma B. Synergistic effects of glutathione and Vit E on ROS mediated ethanol toxicity in isolated rat hepatocytes. Asian J Biol. 2011;6:347-356.

8. Lomaestro BM, Malone M. Glutathione in health and disease: pharmacotherapeutic issues. Ann Pharmacother. 1995;29:1263-1273. doi:10.1177/106002809502901213

9. Skrzydlewska EI, IKI D, Figaszewski Z. Effect of Vit E derivative (U83836E) on membranes of rat liver cells after methanol intoxication. Pol J Environ Stud. 2001;10(2):95-100.

10. Coulter ID, Hardy ML, Morton SC, et al. Antioxidants vitamin C and Vit E for the prevention and treatment of cancer. J Gen Int Med. 2006;21:735-744. doi:10.1111/j.1525-1497.2006.00483.x

11. Biewenga GP, Haenen GR, Bast A. The pharmacology of the antioxidant lipoic acid. Gen Pharmacol. 1997;29:315-331. doi:10.1016/ S0306-3623(96)00474-0 
12. Al-Rasheed NM, Al-Rasheed NM, Abdel Baky NA, et al. Prophylactic role of $\alpha$-lipoic acid and vitamin e against zinc oxide nanoparticles induced metabolic and immune disorders in rat's liver. Eur Rev Med Pharmacol Sci. 2014;18:1813-1828.

13. Griffith OW. Determination of glutathione and glutathione disulfide using glutathione reductase and 2-vinylpyridine. Anal Biochem. 1980;106(1):207-212. doi:10.1016/0003-2697(80)90139-6

14. Schipper ML, Iyer G, Koh AL, et al. Particle size, surface coating, and PEGylation influence the biodistribution of quantum dots in living mice. Small. 2009;5(1):126-134. doi:10.1002/smll.v5:1

15. Ramos LF, Kane J, McMonagle E, et al. Effects of combination tocopherols and alpha lipoic acid therapy on oxidative stress and inflammatory biomarkers in chronic kidney disease. J Ren Nutr. 2011;21(3):211-218. doi:10.1053/j.jrn.2010.08.003
16. Kalender S, Kalender Y, Ogutcu A, Uzunhisarcikli M, Durak D, Açikgoz F. Endosulfan-induced cardiotoxicity and free radical metabolism in rats: the protective effect of Vit E. Toxicology. 2004;202 (3):227-235. doi:10.1016/j.tox.2004.05.010

17. Al-Attar AM. Antioxidant effect of Vit E treatment on some heavy metals induced renal and testicular injuries in male mice. Saudi J Biol Sci. 2011;18(1):63-72. doi:10.1016/j.sjbs.2010.10.004

18. Randle PJ, Kerbey AL, Espinal J. Mechanisms decreasing glucose oxidation in diabetes and starvation: role of lipid fuels and hormones. Diabetes Metab Rev. 1988;4:623-638. doi:10.1002/dmr.v4:7

19. Vasdev S, Ford CA, Parai S, Longerrich L, Gadag V. Dietary alpha-lipoic acid supplementation lowers blood pressure in spontaneously hypertensive rats. J Hypertens. 2000;18:567-573. doi:10.1097/00004872-2000 18050-00009

\section{Publish your work in this journal}

The International Journal of Nanomedicine is an international, peerreviewed journal focusing on the application of nanotechnology in diagnostics, therapeutics, and drug delivery systems throughout the biomedical field. This journal is indexed on PubMed Central, MedLine, CAS, SciSearch ${ }^{\mathbb{R}}$, Current Contents ${ }^{\mathbb{R}} /$ Clinical Medicine, $^{-}$
Journal Citation Reports/Science Edition, EMBase, Scopus and the Elsevier Bibliographic databases. The manuscript management system is completely online and includes a very quick and fair peer-review system, which is all easy to use. Visit http://www.dovepress.com/ testimonials.php to read real quotes from published authors. 